\title{
Restrictions on definiteness in second language acquisition
}

\section{Affirmative and negative existentials in the L2 English of Turkish and Russian speakers}

\author{
Lydia White $^{1}$, Alyona Belikova ${ }^{1}$, Paul Hagstrom ${ }^{2}$, \\ Tanja Kupisch ${ }^{3}$ and Öner Özçelik ${ }^{1}$ \\ McGill University ${ }^{1}$ / Boston University ${ }^{2}$ / University of Hamburg ${ }^{3}$
}

In this paper we investigate whether learners of L2 English show knowledge of the Definiteness Effect (Milsark, 1977), which restricts definite expressions from appearing in the existential there-insertion construction. There are crosslinguistic differences in how restrictions on definiteness play out. In English, definite expressions may not occur in either affirmative or negative existentials (e.g. There is $a{ }^{*}$ the mouse in my soup; There isn't $a{ }^{*}$ the mouse in my soup). In Turkish and Russian, affirmative existentials observe a restriction similar to English, whereas negative existentials do not. We report on a series of experiments conducted with learners of English whose L1s are Turkish and Russian, of intermediate and advanced proficiency. Native speakers also took the test in English, Turkish and Russian. The task involved acceptability judgments. Subjects were presented with short contexts, each followed by a sentence to be judged as natu$\mathrm{ral} /$ unnatural. Test items included affirmative and negative existentials, as well as items testing apparent exceptions to definiteness restrictions. Results show that both intermediate and advanced L2ers respond like English native speakers, crucially rejecting definites in negative existentials. A comparison with the groups taking the test in Russian and Turkish confirms that judgments in the L2 are quite different from the L1, suggesting that transfer cannot provide the explanation for learner success.

Keywords: Definiteness Effect, existentials, Turkish, Russian 


\section{Introduction}

It has long been known that second language learners and speakers (henceforth, L2ers) have problems in acquiring article systems, particularly in the case of those whose mother tongues (L1s) lack articles (e.g. Huebner, 1985; Robertson, 2000; Thomas, 1989; for recent approaches, see papers in Garcia-Mayo \& Hawkins, 2009). Production errors include omission of articles in contexts in which they are required (see (1a)), as well as inappropriate patterns of suppliance, such as substitution of definites for indefinites (see (1b)) or vice versa, and oversuppliance in contexts where no article would be required, for example with indefinite mass nouns, abstract nouns or plurals (see (1c)).

(1) a. And she made phone call to someone.

(White, 2008a)

b. She take the bath.

c. I was like in the space.

There have been a number of suggestions that at least some of these error types are the result of problems relating to how, if at all, a [ \pm definiteness] feature is represented in the interlanguage grammar. Semantic, morphosyntactic, pragmatic and phonological accounts of L2 article use have been offered. For example, there have been suggestions that: (i) L2ers whose L1s lack articles fluctuate between definiteness and specificity as the feature that determines article choice in the L2 (e.g. Ionin, Ko, \& Wexler, 2004); (ii) permanent morphosyntactic deficits are implicated, particularly in cases where the L2 realizes an uninterpretable definiteness feature not found in the L1 (e.g. Tsimpli \& Mastropavlou, 2007); (iii) persistent pragmatic problems arise, interacting with processing difficulties (e.g. Trenkic, 2007); (iv) effects of L1 prosodic representations are such that, in certain circumstances independent of the issue of definiteness, English articles cannot be pronounced (e.g. Goad \& White, 2009).

In contrast, in this paper, we show that L2ers whose mother tongues lack articles can achieve native-like restrictions on definiteness, suggesting no representational deficit as far as this feature is concerned. We focus on the so-called Definiteness Restriction (Milsark, 1977, amongst others), more commonly referred to as the Definiteness Effect (DE), investigating unconscious knowledge of this restriction on the part of Turkish-speaking and Russian-speaking learners of English. We compare the performance of the L2ers to the performance of native speakers of English on this phenomenon and also to the performance of native speakers of Turkish and Russian in their L1s; we show that L2ers' treatment of English accords with the behaviour of English native speakers rather than with the behaviour of Turkish or Russian native speakers. 


\section{The Definiteness Effect in English}

Definiteness in English DPs is realized by means of articles, as well as other determiners, such as demonstratives, possessives, quantifiers and numerals; in addition, proper names and pronouns are definite. In the English existential there-insertion construction, there is a restriction, such that indefinite DPs are permitted while definite expressions are excluded. This distinction applies to articles (compare (2a) and (2b)), as well as to other determiners (compare (2c) and (2d)). The restriction also applies in the case of negative existentials, as can be seen by comparing (2e) and (2f).

(2) a. There is still a customer in the store.

b. ${ }^{*}$ There is still the customer in the store.

c. There are still some customers in the store.

d. ${ }^{*}$ There is still every customer in the store.

e. There isn't a customer in the store.

f. *There isn't the customer in the store.

Milsark (1977) distinguishes weak expressions from strong and argues that this distinction lies at the heart of the restriction on definiteness: only weak expressions can occur in the existential there construction. Definite DPs are classed as strong, whereas indefinite DPs are weak. The distribution of strong and weak expressions is shown in Table 1.

Table 1. Weak and strong expressions in English

\begin{tabular}{ll}
\hline Weak (indefinite) & Strong (definite) \\
\hline A & the \\
some, many, few, no, etc. & all, most, every, each, etc. \\
cardinal numbers & demonstratives, possessives \\
(one, two, three, etc.) & $($ this, that, $m y$, his, etc.) \\
zero articles & personal pronouns, proper names \\
(bare plurals, mass nouns) & \\
\hline
\end{tabular}

There are apparent exceptions to the restriction against definite DPs. For example, deictic uses of there (as opposed to existential) can be followed by either definite or indefinite DPs, as illustrated in (3a). Lists (even of a single item) constitute another case where definite and indefinite expressions are both permitted (Rando \& Napoli, 1978), as shown in (3b). ${ }^{1,2}$

(3) a. Look, there's the/a bus.

b. How can we get to the airport? Well, there's the airport bus or a taxi. 
There have been a number of approaches to explaining the restriction on definiteness, including syntactic (e.g. Safir, 1987), semantic (e.g. Barwise \& Cooper, 1981; Keenan, 1987; Milsark, 1977), and pragmatic (e.g. Abbott, 1993; Leonetti, 2008; Zucchi, 1995), as well as combinations thereof (e.g. Lumsden, 1988; McNally, in press). For the time being, we set these accounts to one side, as the phenomenon we investigate is to some extent independent of how it is ultimately accounted for; however, we return to this issue in the discussion, offering some speculation on what underlies certain cross-linguistic differences on the restriction, and what might serve as 'triggering data' in the case of L2 acquisition in circumstances where the L1 and L2 differ in how the DE plays out. These differences are presented in the next section.

\section{Cross-linguistic differences in the Definiteness Effect}

As Table 1 illustrates, the realization of the weak versus strong distinction is not limited to the article system; definiteness can be expressed in other ways. This means that even languages that do not express a definiteness contrast via articles may nevertheless show definiteness restrictions. In the present paper, we focus on Turkish, a language that has an indefinite article (unstressed bir) but no definite article, ${ }^{3}$ and on Russian, a language without articles. While both of these languages are subject to a definiteness restriction, it applies in a narrower range of contexts than in English.

Existential sentences typically contain a subject NP whose existence is under discussion (sometimes referred to as the 'pivot') and a location (the 'coda'). It has been argued that, in languages without an expletive in the existential construction, only a word order with the locative preceding the subject signals an existential interpretation. A word order with the subject before the locative is taken to indicate a predicate locative (e.g. Freeze, 1992). While we agree that sentences with the locative first are indeed existential, we maintain that existential interpretations are also possible on the other word order, as we will demonstrate for both Turkish and Russian.

Turkish is a null subject language, with no overt expletives. In Turkish, the existential predicate in affirmative cases is var ('exist'), whereas negative existentials are expressed by means of yok ('not exist'). The canonical word order in Turkish is Subject-Object-Verb (SOV), but other orders are possible, and are sometimes motivated by considerations of definiteness (see Kornfilt, 1997; Özçelik \& Nagai, 2011). Indefinite expressions tend to be closer to the verb than definites; in a nonexistential sentence with a locative, for instance, an indefinite subject usually follows the locative, as in (4a), whereas a definite subject precedes it, as in (4b). When 
a definite subject is focused, however, it occurs in the immediately pre-predicate position; see (5).

(4) a. Dükkana çocuk geldi. store.to child come.past 'A child came to the store.'

b. Çocuk dükkana geldi. child store.to come.past 'The child came to the store'.

(5) Dükkana çocuk geldi. store.to child come.past 'It is the child that came to the store (not his/her parents).'

Affirmative existentials in Turkish, as in English, are subject to a restriction against definite expressions; only weak determiners are permitted in this construction (Enç, 1991), as can be seen by comparing (6a) with (6b) and (6c), which are ungrammatical regardless of word order. ${ }^{4}$

(6) a. Dükkanda hala birkaç müşteri var. store.at still several customer exist

'There are still several customers in the store.'

b. ${ }^{\star}$ Dükkanda hala Ali var. store.at still Ali exist

'There is still Ali in the store.'

c. ${ }^{*}$ Ali hala dükkanda var.

Ali still store.at exist

'There is still Ali in the store'.

Negative existentials, on the other hand, do not show a definite/indefinite contrast in Turkish; both indefinite and definite DPs are grammatical, as shown in (7). ${ }^{5}$ In other words, Turkish affirmative existentials mostly behave like English, whereas negative existentials do not. Note, in particular, that negative existentials with definite DPs (including proper nouns) are grammatical regardless of whether the subject precedes or follows the locative, unlike affirmative existentials; compare (7b) and $(7 c)$ with $(6 b)$ and $(6 c)$.

(7) a. Dükkanda çok müşteri yok. store.at many customer not.exist 'There aren't many customers in the store.'

b. Dükkanda Ali yok.

store.at Ali not.exist

'There isn't Ali in the store.' 
c. Ali dükkanda yok.

Ali store.at not.exist

'There isn't Ali in the store.'

The position we are assuming here is that strong DPs are allowed in negative existentials in Turkish (as well as Russian, discussed below). It must therefore be demonstrated that negative sentences with strong DPs are in fact existential ('There isn't Ali in the store') and not locative ('Ali isn't in the store').

In Turkish, there is a lexical distinction between negative existentials and negative locatives that shows the difference clearly. The predicate $y o k$ is only used to express non-existence; other negatives are formed with değil, as shown in the following examples. In (8a), we see a predicate locative. The appropriate negation for this is shown in (8b); the word order with locative first is not grammatical in this case, as shown in (8c). This contrasts with existentials, as in (7b).

(8) a. Ali dükkanda.

Ali store.at

'Ali is in the store.'

b. Ali dükkanda değil.

Ali store.at not

'Ali is not in the store.'

c. ${ }^{*}$ Dükkanda Ali değil

store.at Ali not

'Ali is not in the store.'

To analyze (7c) as a locative rather than an existential would require the assumption that only in this one case can yok be substituted for değil. Furthermore, neither $(7 b)$ nor (7c) require focus in order to be grammatical. Focus can improve the acceptability of sentences where a strong DP occurs between a locative phrase and the predicate, both for regular verbs, as in (5), and in affirmative existentials, as in (6b), resulting in an interpretation like 'It is ALI that is in the store (not Jack)'; in contrast, (7b) and (7c) are grammatical independent of focus. We conclude that the sentences in (7b) and (7c) are true negative existentials, hence that Turkish permits strong DPs in negative existentials.

Russian, like Turkish, is a null subject language, with no overt expletives. In the experiment reported here, we focus on the present tense, where Russian uses distinct predicates to express existence (est') and non-existence (net). Unlike regular verbs, est' and net do not inflect or agree with their subjects; subjects with est' are nominative, while subjects with net are obligatorily genitive.

The constraints holding of existential constructions in Russian match those holding in Turkish. As can be seen by comparing (9a) with (9b) and (9c), a DE is observed in affirmatives, whereas (9d) to (9f) illustrate the lack of any such effect 
in negatives; in particular, (9f) is grammatical, even though the DP is definite. In other words, affirmative existentials in Russian behave like those in English, exhibiting a definiteness effect, whereas negative existentials differ from English, showing no definite/indefinite contrast (see Borschev \& Partee, 1998; Padučeva, 2000 , amongst others).

(9) a. V magazine vse eshhe est' kakieto pokupateli.

in store still exist some.nom customers.nom

'There are still some customers in the store.'

b. ${ }^{*} \mathrm{~V}$ magazine vse eshhe est' Ivan.

in store still exist Ivan.nom

'There is still Ivan in the store.'

c. ${ }^{\star}$ Ivan vse eshhe est' $\mathrm{v}$ magazine.

Ivan.nom still exist in store.

'There is still Ivan in the store.'

d. V magazine net nikakikh pokupatelej.

in store not.exist no.gen customers.gen

'There aren't any customers in the store'.

e. (?) $\mathrm{V}$ magazine net Ivana.

in store not.exist Ivan.gen

'There isn't Ivan in the store.'

f. Ivana net $\mathrm{v}$ magazine.

Ivan.gen not.exist in store

'There isn't Ivan in the store.'

It is also important to note that with weak DPs, the preferred word order in an existential (under neutral intonation) is 'locative - est'/net - subject', as in (9a) and (9d); in contrast, with strong DPs in negative existentials, the usually preferred word order is 'subject - net - locative', as in (9f) (see Partee \& Borschev (2007) for an overview and discussion). Thus, the word order in the negative existential in (9f) sounds somewhat more natural than (9e).

As was the case for Turkish, it is important to show for Russian that sentences like (9f) are truly existential, rather than locative. While Russian does not show a lexical distinction between all negative locatives and negative existentials, ${ }^{6}$ the distinction is instead made evident in the surface form through case marking. Generally, subjects in negative contexts in Russian may show an optional alternation between genitive case and nominative ("genitive of negation"). ${ }^{7}$ However, subjects of Russian negative existentials are obligatorily genitive. According to some authors, sentences with genitive definite subjects are not true existentials (e.g. Babby, 1980). We, however, maintain that they are, on the basis of arguments such as the following. 
Consider (10) and (11). The sentences in (10) contain a weak DP ('nobody'). It is uncontroversial that (10a) (with an NP marked nominative and subject-before-locative word order) is locative, while (10b) (with an NP marked genitive and locative-before-subject order) is existential. Sentence (10a) is primarily about a location; the locative cannot be omitted and the location is not presupposed to exist (the sentence can be felicitously followed by something like 'there is no hospital around here'). Sentence (10b), on the other hand, is about non-existence at a particular location; the location is given and is presupposed (the locative can be dropped and (10b) cannot be felicitously followed by 'there is no hospital around here').

Crucially, as argued by Partee and Borschev (2002), sentences like (11a) and (11b), with strong DPs, show the same contrasts in presupposition, natural contexts, etc., as sentences like (10a) and (10b), suggesting that the (a) version of the sentence is locative and the (b) version existential, even though the word order is the same in both cases; in other words, the essential difference between (11a) and (11b) is case, not word order. ${ }^{8}$

(10) a. Nikto ne byl $\mathrm{v}$ bolnice. nobody.nom not was.masc in hospital 'Nobody was in hospital.'

b. V bolnice nikogo ne bylo. in hospital nobody.gen not was.neut 'There was nobody in the hospital.'

(11) a. Ivan ne byl $\mathrm{v}$ bol'nice. Ivan.nom not was.masc in hospital 'Ivan wasn't in hospital.'

b. Ivana ne bylo $\mathrm{v}$ bol'nice. Ivan.gen not was.neut in hospital 'There wasn't Ivan in the hospital.'

There is one further consideration that is relevant here. Russian possessive constructions have been related to existentials (rather than to locatives) by many linguists (e.g. Jung, 2011; Kondrashova, 1996, amongst others). In negative possessives, there is no genitive/nominative alternation in the past tense; rather, genitive is obligatory. In (12a), with a nominative subject, the only interpretation is as a locative; on the other hand, (12b), which has a genitive subject, is ambiguous between existential and possessive readings. To the extent that possessive and existential constructions are related, these facts confirm that genitive is indicative of existentiality, while nominative is indicative of locativity. 
(12) a. Nikto ne byl u menja.

nobody.nom not was.masc at me

'Nobody was at my place.' (NOT 'I didn't have anybody.)

b. U menja nikogo ne bylo.

at me nobody.gen not was.neut

'I didn't have anybody' or 'There was nobody at my place.'

To summarize, both Turkish and Russian allow strong DPs in constructions that we have argued, for each language independently, are true negative existentials. This distinguishes Turkish and Russian from English, which allows strong DPs in neither affirmative nor negative existentials.

In this paper, we examine whether L2ers whose mother tongues are Turkish or Russian come to know how restrictions on definiteness play out in English. Assuming that L2ers acquire the fact that the English article system embodies a definiteness contrast ( $a$ versus the), the situation regarding the DE is nevertheless rather subtle, as we have seen: with respect to DPs involving other determiners, affirmative existentials work in similar fashion in the L1 and L2, whereas negative existentials do not.

\section{Previous research on the DE in $\mathrm{L} 2$ and some open questions}

Even though the L2 acquisition of articles has been extensively researched over the years (see Thomas (1989) for an overview of earlier research and Garcia-Mayo \& Hawkins (2009) for more recent perspectives), there has been relatively little examination of the DE. Such research has mostly involved spontaneous (or relatively spontaneous) production data. For example, in a case-study of an advanced English L2 speaker with Turkish mother tongue, White (2003) found no DE violations, although the subject did make errors in article usage, in the form of omission. Lardiere (2004), in her case-study of Patty, a steady-state L2 speaker, with Chinese as L1, similarly reports no DE violations, Chinese being another language without articles. White (2008b) reports no DE violations in elicited production data from intermediate level Turkish-speaking and Chinese-speaking learners of English.

Some recent studies have also looked at whether there are ERP effects relating to the DE. King, Steinhauer and White (2006) investigated the DE in low and high intermediate Chinese-speaking learners of English, in an ERP study that required them to make grammaticality judgments. The low intermediate subjects did not distinguish between DE violations and equivalent grammatical sentences, nor were there any ERP effects. The more advanced subjects, on the other hand, did distinguish between DE violations and non-violations and showed P600 effects, which are generally associated with recognition of violations of grammaticality. 
Drury, E. White, L. White and Steinhauer (2009) similarly found evidence for P600 effects in advanced French speakers and Chinese speakers acquiring English but not in low proficiency groups with the same L1s. ${ }^{9}$ In summary, results from previous studies suggest that L2ers become sensitive to the English DE, even when the L1 lacks an article or articles.

However, a number of questions arise from these studies, suggesting the need for further investigation. Open questions include the following:

(i) The findings based on English production data depend on rather infrequent spontaneous production of there-insertion. The failure to find DE violations may simply reflect the absence of a sufficient number of contexts suitable for uttering an existential expression. Furthermore, it is conceivable that L2ers might in fact allow definite expressions in existential constructions but disprefer them and, accordingly, avoid producing them.

(ii) When analyzing production data, one must often guess what contexts the speaker had in mind. In the case of traditional grammaticality judgment tasks, contexts are rarely supplied. For the DE, it is crucial to establish the context, since it is only existential sentences that show the effect; list and deictic readings permit both definites and indefinites. In other words, the same sentence might be judged to be grammatical in one context and ungrammatical in another. In addition, if grammaticality judgments are made in isolation, sentences with definite articles will often be infelicitous due to a presupposition failure; on first mention, the definite article is usually excluded, because no presupposition has been established to render the DP in question definite. Thus, if suitable contexts are not supplied, rejection of existential sentences with definite articles does not necessarily imply knowledge of the DE; rather, it might indicate recognition of presupposition failure (which is often explicitly taught in L2 classrooms).

(iii) Previously observed success with respect to the DE might be attributable to L1 transfer, even in the case of L1s without articles. As we have seen, languages do not restrict the expression of definiteness to an article system but have a range of other determiners, including demonstratives, possessives, numerals, quantifiers, etc., some of which are strong and some weak. Hence, any success with affirmative existentials in L2 could be attributed solely to L1 transfer. Furthermore, knowledge of the English DE presents a 'subset problem' in terms of error-driven acquisition from exposure to positive evidence. Any existentials encountered in the L2 input would be consistent with a corresponding existential construction permitted in the L1. In other words, there is nothing in the L2 input to discourage L1 transfer in this domain. Investigation of negative existentials is therefore crucial. If L2ers prove not to have problems with negative existentials when the L1 and L2 differ, this suggests that transfer alone cannot be responsible for L2ers' success. 
(iv) Previously observed success with respect to the DE might be attributable to learner sensitivity to frequently occurring patterns in the L2 input (Robert BleyVroman, personal communication) or to effects of instruction (Boping Yuan, personal communication). In other words, There is $a \ldots$ is a relatively frequent pattern in English and may also be explicitly taught. In order to exclude such explanations, it is necessary to include grammatical sentences that are less frequent and unlikely to be taught, for example, negative existentials, and existentials involving a variety of determiners (not just $a$, the and some), as well as deictic and list readings, which do not obey the 'rule'.

For reasons such as these, we devised an acceptability judgment task incorporating contexts and, crucially, testing negative existentials as well as affirmative. We investigate, by means of a series of experiments, whether L2ers whose L1s are Turkish or Russian observe the DE in English. Transfer from the L1 would result in an inappropriate analysis in the case of negative existentials. In fact, as we will see, at the levels of proficiency that we tested, there is little evidence for transfer.

\section{Experiments}

In this section, we describe a series of experiments investigating unconscious knowledge of the DE by L2ers and native speakers. The first experiment looks at the L2 English of Turkish-speakers, the second at the L2 English of Russian speakers; in both cases, L2ers are compared to native speakers of English. In the third and fourth experiments, we investigate native speaker knowledge of the DE in Turkish and Russian. ${ }^{10}$ Because the four experiments share the same task (with some variations), we describe the methodology first.

\subsection{Task}

The task was an acceptability judgment task, which was extensively piloted before being finalized. The English version consisted of 90 semi-randomized test items, presented on a computer screen. The Turkish and Russian versions had fewer items, for reasons that will be explained below. Each test sentence was preceded by a short context. Subjects were instructed to read the context and then to decide whether the sentence that appeared beneath it was natural or unnatural in the context. In other words, they were not asked for an outright grammaticality judgment: although all ungrammatical items in our test are either unacceptable or infelicitous in the given context, in other contexts many of them could be acceptable. If subjects judged a sentence to be unnatural, they were asked to type in a correction. 
Examples are presented in Figures 1 to 5. Figure 1 illustrates a natural affirmative existential with the indefinite article; Figure 2 shows an unnatural affirmative existential with the definite article; Figure 3 presents a natural negative existential involving a weak quantifier; Figure 4 illustrates an unnatural negative existential involving a proper name (i.e. a definite expression). Such existentials are grammatical in the L1 but not the L2. Figure 5 shows an example of a natural definite list reading.

Care was taken to ensure that the crucial DP in the test sentence did not appear in exactly the same form in the context, in order to avoid a response bias towards accepting DPs which subjects had previously seen. In the definite cases, the contexts established the referent in the discourse prior to the test sentence, rendering the definite article felicitous in principle. This can be seen in Figure 2, where the name Dr. Salter appears in the context and then the DP the doctor appears in the test item. In other words, if subjects appropriately reject this sentence, we can rule out the possibility that the rejection is due to a presupposition failure.

Tom has to make copies of a report but the photocopier has broken
down. He asks the secretary what to do. She suggests using another
machine, saying:
There's a reliable copy machine downstairs.
How natural is this sentence in this context? If you choose
'unnatural', please correct the sentence.
natural not sure unnatural
Correction:

Figure 1. Natural affirmative existential item (weak)

\begin{tabular}{|c|c|}
\hline & $\begin{array}{l}\text { Anne is feeling sick, so she makes an appointment to see Dr. Salter. } \\
\text { She arrives early and the nurse tells her to go right in, saying: } \\
\text { There's the doctor here already. }\end{array}$ \\
\hline & $\begin{array}{l}\text { How natural is this sentence in this context? If you choose } \\
\text { 'unnatural', please correct the sentence. } \\
\text { natural not sure unnatural } \\
\text { Correction: }\end{array}$ \\
\hline
\end{tabular}

Figure 2. Unnatural affirmative existential item (strong)

\begin{tabular}{|c|c|}
\hline & $\begin{array}{l}\text { John was having a party. When Mary arrived, John suggested that } \\
\text { she should join the other guests outside. He said: } \\
\text { There aren't many people inside. }\end{array}$ \\
\hline & $\begin{array}{l}\text { How natural is this sentence in this context? If you choose } \\
\text { 'unnatural', please correct the sentence. } \\
\text { natural not sure unnatural } \\
\text { Correction: }\end{array}$ \\
\hline
\end{tabular}

Figure 3. English: Natural negative existential (weak) 


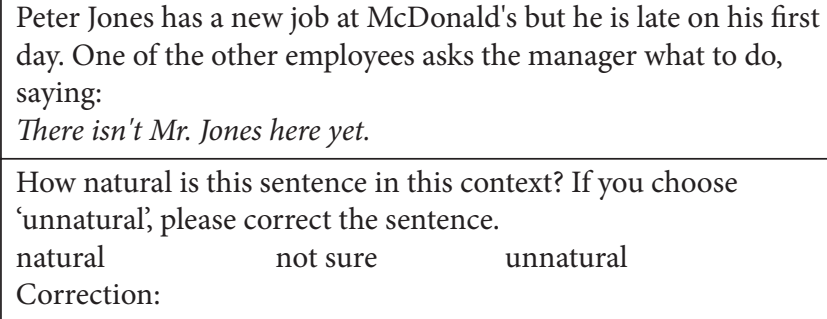

Figure 4. Unnatural negative existential item (strong)

\begin{tabular}{|c|c|}
\hline & $\begin{array}{l}\text { Peter and Sam need to relax after a difficult exam. Peter asked Sam } \\
\text { if they had anything to drink in the house. Sam replied: } \\
\text { There's the bottle of wine we bought yesterday. }\end{array}$ \\
\hline & $\begin{array}{l}\text { How natural is this sentence in this context? If you choose } \\
\text { 'unnatural', please correct the sentence. } \\
\text { natural not sure } \\
\text { Correction: }\end{array}$ \\
\hline
\end{tabular}

Figure 5. Natural list item

Abbott observes that English existentials typically do not presuppose the existence of their referents and can occur "naturally at the beginning of a discourse" (1993:42). In other words, they do not require a discourse context. On the other hand, expressions which presuppose the existence of their referents (including those which other people classify as list readings), require a context to make them natural. In the case of list items, then, such as the one in Figure 5, the intention of the context is to render the definite DP natural. For the crucial infelicitous test items, on the other hand, while the contexts render the definite DPs plausible (by establishing the relevant presupposition), we aimed to ensure that the definite expressions would NOT sound natural, since the context precludes a list reading (see Figures 2 and 4).

\subsection{Sentence types: English version}

There were 18 sentence types tested, with 5 test items per type. Test items (all preceded by contexts, as discussed above) include grammatical and ungrammatical existentials, and apparent exceptions to definiteness restrictions (namely, deictic and list readings), as well as sentences controlling for other aspects of (in)definiteness. There were 10 ungrammatical types (for a total of 50 ungrammatical items) and 8 grammatical types (40 grammatical items).

The items in (13) illustrate grammatical and ungrammatical affirmative existentials with articles and other determiners. Note that there were two types of 
grammatical cases (i.e. weak DPs, involving indefinite articles or weak quantifiers), whereas there were four different ungrammatical cases (i.e. strong DPs, involving definite articles, proper names, possessives or strong quantifiers), some of which are illustrated in the examples below. All these items test whether L2ers are sensitive to the DE in situations where strong and weak determiners behave similarly in the L1 and L2.

(13) Affirmative existentials

a. Grammatical with indefinite article There's a reliable copy machine downstairs.

b. Ungrammatical with definite article There's the book at the store now.

c. Grammatical with weak determiner There are still three people there.

d. Ungrammatical with strong determiner There are most children in the garden, I think.

The items in (14) illustrate the equivalent sentence types for negative existentials. These test sensitivity to the DE when the L1 and L2 behave differently, as is the case for strong DPs with proper names, possessives or quantifiers; for example, (14d) is ungrammatical in English but its equivalents in Turkish and Russian are grammatical.

(14) Negative existentials

a. Grammatical with indefinite article There isn't a suitable bowl here.

b. Ungrammatical with definite article There isn't the bowl here.

c. Grammatical with weak determiner There isn't another copy machine here.

d. Ungrammatical with strong determiner Oh! There aren't most guests here yet.

The examples in (15) show grammatical list (15a) and deictic (15b) sentences, which are included in order to determine whether L2ers simply reject all definite expressions with there, as might be expected if indeed they are instructed about the use of indefinites in there-insertion contexts.

(15) List and deictic

a. Well, for a start, there's the moon.

b. Look. There's the mouse again. 
Finally, the sentences in (16) illustrate the sentence types that did not involve existentials or there. Given that the definite article in the existential test items is always ungrammatical, sentences like (16a) are included to eliminate the possibility that L2ers simply reject all subjects with a definite article. In other words, we wish to ensure that L2ers do not simply adopt a strategy of always rejecting definite articles; sentences like those in (16a) (together with those in (15)) allow us to determine whether this might be happening. Conversely, since all test items involving the indefinite article in there-insertion contexts are grammatical, sentences like (16b) and (16c) are included to check that L2ers treat indefinites appropriately in non-existential contexts, accepting indefinites like (16b) in contexts that render them grammatical and rejecting indefinites like (16c) in contexts that render them ungrammatical.

(16) Control items

a. Grammatical definite subject The next job candidate is waiting outside.

b. Grammatical indefinite subject A key has been found by the coffee machine.

c. Ungrammatical indefinite subject ${ }^{11}$ A kitchen stove is broken.

Some minor modifications were made to the task after the Turkish speakers took it and before the Russian speakers did. In the version administered to the Turkish speakers, there were 5 grammatical locative sentences with definite subjects, involving a proper name, such as (17):

(17) Professor Black seems to be in his office today.

These items, which tested grammatical definite subjects without there, were replaced by 5 items with subject DPs with a definite article (i.e. sentences like (16a)).

In the case of the negative existentials, a couple of demonstratives were included in the first version of the task. These were subsequently removed, for the sake of consistency, and replaced with strong quantifiers. Finally, on the basis of the performance of the native speaker controls, some very minor modifications were also made to some of the contexts and to some of the test items. The Turkish and Russian versions of the task were based on the second version of the English test.

\subsection{Sentence types: Turkish and Russian versions}

Our task (contexts and test sentences) was translated into Turkish and Russian, ${ }^{12}$ in order to administer it to native speakers of the L1s in question. Recall that we are assuming that negative existentials in Turkish and Russian contrast with 
English in not showing a DE. With the exception of Beaver, Francz and Levinson (2005) who discuss Russian but not Turkish, we have not found any discussion of this difference in the literature. We, therefore, feel that it is essential to test our assumption on native speakers of Turkish and Russian judging their L1s.

The Turkish and Russian tests included fewer items, because of the absence of a definiteness contrast with articles in these languages, resulting in a total of 60 test items in the Turkish version of the test and 55 in the Russian version. Turkish and Russian versions of the task include three ungrammatical sentence types, as well as fillers, for a total of 25 ungrammatical items; the Turkish version includes seven grammatical sentence types ( 35 items), while the Russian version has six grammatical types (30 items).

Test items, all preceded by contexts, as in the English version of the test, include grammatical and ungrammatical existentials. Examples of affirmative existentials are shown in (18) and (19); negative existentials are found in (20) and (21).

(18) Affirmative existentials (Turkish)

a. Grammatical with weak determiner

Dışarıda hala üç kişi var. outside still three person exist 'There are still three people outside.'

b. Ungrammatical strong determiner Sanırım, çocukların çoğu bahçede var. think.pres.1s child.pl.gen most garden.loc exist 'I think there are most of the children in the garden.

(19) Affirmative existentials (Russian)

a. Grammatical with weak determiner Tam eshhe est' tri cheloveka. there still exist three people 'There are still three people there.'

b. Ungrammatical with strong determiner Mne kazhetsja, bol'shinstvo detej est' v sadu. me.dat seems most.nom children.gen exist in garden 'It seems to me that there are most children in the garden.'

(20) Negative existentials (Turkish)

a. Grammatical with weak determiner Bildiğim kadarıla, burada başka bir fotokopi makinesi yok. know.rc.1s as.much.as.with here other a photocopy machine not.exist 'As far as I know, there isn't another copy machine here.' 
b. Grammatical with strong determiner

Hayır, davetlilerin çoğu henüz salonda yok.

no guest.pl.gen most yet lounge.loc not.exist

'No, there aren't most of the guests here yet.'

(21) Negative existentials (Russian)

a. Grammatical with weak determiner

$\mathrm{V}$ nashem zdanii net drugogo kseroksa.

in our building not.exist another.gen copy-machine.gen

'There isn't another copy machine in our building.'

b. Grammatical with strong determiner

A bol'shinstva gostej eshe net.

oh most.gen guests.gen still not.exist

'Oh. There aren't most guests (here) yet.'

Figures 6 and 7 further illustrate items (contexts and test sentences) where Turkish and Russian differ crucially from English, namely negative existentials with definite subjects, ${ }^{13}$ which are grammatical in both languages.

Mehmet Öz McDonalds'da yeni bir işe başlar; ama ilk günden işe
geç kalır. Orada çalışan elemanlardan biri patronları Ömer Bey'e bu
durumda ne yapmaları gerektiğini sorar ve durumu şöyle izah eder:
(Mehmet Öz starts a new job at McDonalds, but is late for the job on
the first day. One of the staff members working there asks their
manager, Mr. Ömer, what they should do in this situation and
explains as follows:)
Ömer Bey, Mehmet Bey henüz işyerinde yok. Ne yapmamız
gerekiyor?
(Mr. Ömer, there isn't Mr. Mehmet in the workplace yet. What
should we do?)

Figure 6. Turkish: Natural negative existential (strong)

Сергей Смирнов опаздывает на свою новую работу. Один из
сотрудников спрашивает менеджера, что им делать, пояснив:
(Sergej Smirnov is late for his new job. One of his co-workers asks
the manager what to do, explaining:)
Смирнова все еще нет на месте.
(There isn't Smirnov at his workplace yet.)

Figure 7. Russian: Natural negative existential (strong)

\subsection{Data analysis (all experiments)}

Recall that subjects are asked to make a correction whenever they indicate that a sentence seems unnatural in the given context. The purpose of the corrections is 
to ensure that subjects are responding relevantly. For example, if the sentence in Figure 2 is corrected to The doctor is here already, this would count as relevant, since the removal of there while retaining a definite subject suggests sensitivity to the DE, as would a correction like There's a doctor here already (albeit somewhat infelicitous given this particular context), where the DP has been rendered indefinite. Corrections which fail to correct DE violations, such as There's Dr. Salter here already, where one definite DP is substituted for another, are taken to indicate lack of sensitivity to the DE. Irrelevant corrections, such as There's the doctor here now, are treated as if no correction had been made. Subjects' corrections were examined and classified as relevant or irrelevant according to these criteria. Any items where subjects failed to make a correction were removed from the analysis.

Subjects were tested individually (on a computer) on the task described in the previous section. Responses were automatically recorded and subsequently downloaded into excel for analysis. For all results reported below, we conducted two factor mixed ANOVAs, followed by post hoc tests (Scheffé, Tamhane's T2 or paired t-tests with a Bonferroni correction, as appropriate) and one factor ANOVAs, to determine the source of any differences (PASW Statistics 18). ${ }^{14}$

\subsection{Experiment 1: Turkish-speaking L2ers}

\subsubsection{Subjects}

Our first experiment was conducted with adult Turkish-speakers whose L2 was English. Subjects were attending an English-medium university in Istanbul, Turkey. Their average age was 21 years and 6 months (range 19-28 years) and they had had an average of nine years and six months of instruction in English as a foreign language in school (starting from about age 9) and at university. On the basis of a cloze test, ${ }^{15}$ subjects were divided into two proficiency levels: intermediate $(\mathrm{n}=12)$ and advanced $(n=10)$. There was also a control group of 10 native speakers of English.

\subsubsection{Results}

In Figure $8,{ }^{16}$ we present overall results on existential sentences, collapsing the sentence types involving articles and other determiners. Mean acceptance of grammatical (i.e. weak) and ungrammatical (i.e. strong) cases is compared, in both affirmative and negative existentials.

A two factor mixed ANOVA shows no effect for group $(\mathrm{f}(2,29)=2.8, p=0.076)$, a significant main effect for sentence type $(\mathrm{f}(3,87)=575.6, p<0.001)$ and a significant interaction $(f(6,87)=12, p<0.001)$, due to the fact that only the intermediate group accept grammatical affirmative existentials significantly more often than grammatical negative existentials. According to paired t-tests, participants show 


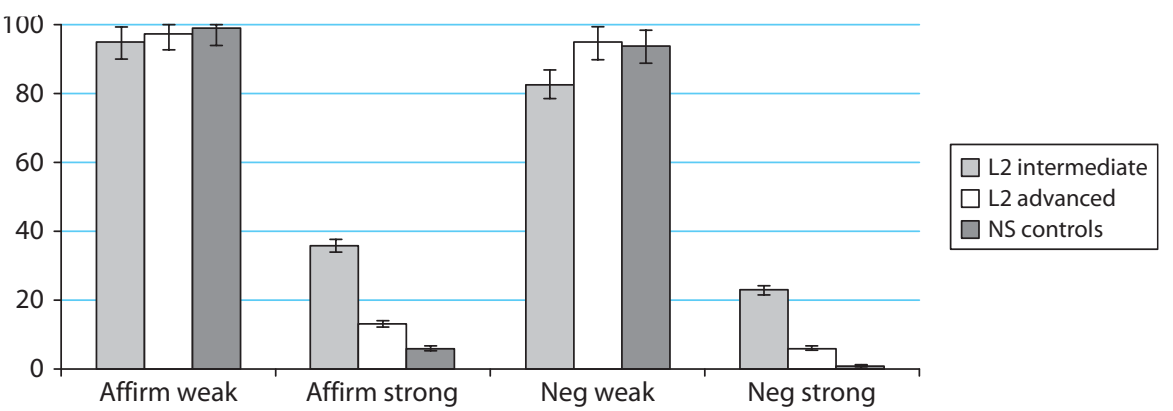

Figure 8. English existentials: acceptance by Turkish-speaking L2ers (\%)

a significant difference in acceptance of grammatical and ungrammatical existentials, whether affirmative or negative $(p<0.001)$. Crucially, both the intermediate and advanced L2ers reject strong DPs in negative existentials, even though these are grammatical in Turkish.

Figures 9 and 10 present the results for the ungrammatical affirmative and negative existentials respectively, divided into subtypes, namely definite articles, proper names, possessives and strong quantifiers. We did not anticipate any differences between the sub-types, with the possible exception of definite articles. Given their absence in the L1, it is conceivable that these items might be judged less accurately than the others. This turned out only partially to be the case, and only for the intermediate subjects.

Figure 9 shows the results on definite affirmatives. A two factor mixed ANOVA shows a significant main effect for group $(\mathrm{f}(2,29)=17, p<0.001)$, a significant main effect for sentence type $(\mathrm{f}(2.6,76.1)=5, p<0.01)$ and a significant interaction $(\mathrm{f}(5.3,76.1)=3.4, p<0.01)$. Post hoc Scheffé tests reveal no significant difference between native controls and advanced L2ers, while intermediates perform differently from both native controls $(p<0.001)$ and advanced L2ers $(p<0.005)$. According to one factor repeated measures ANOVAs, native controls and advanced L2ers

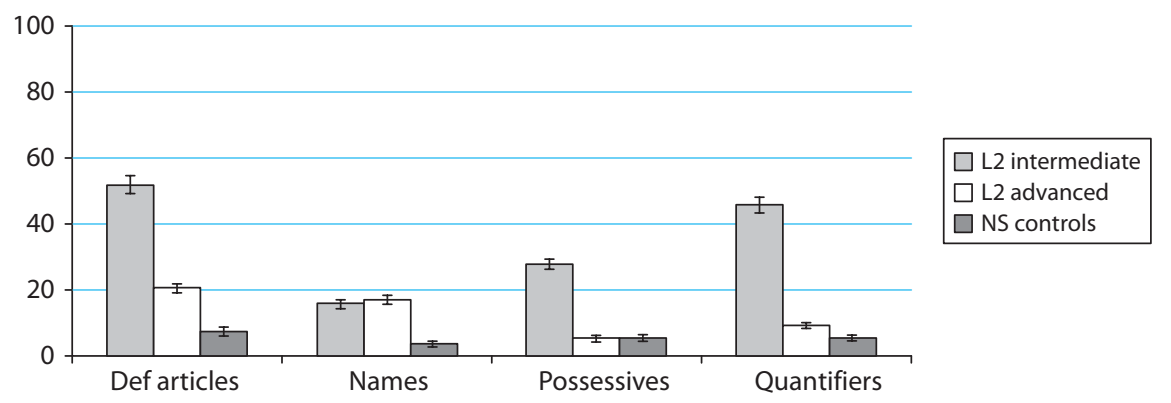

Figure 9. Ungrammatical affirmative existentials: acceptance by Turkish-speaking L2ers (\%) 


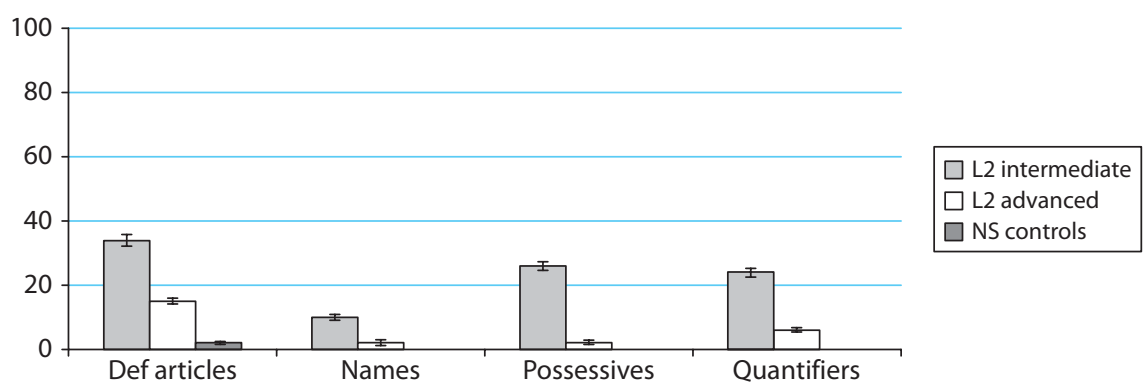

Figure 10. Ungrammatical negative existentials: acceptance by Turkish-speaking L2ers (\%)

show no significant differences between the 4 types of ungrammatical affirmative existentials, while intermediate L2ers accept ungrammatical definite articles significantly more often than proper names $(p<0.001)$ and possessives $(p<0.05)$.

In the case of strong expressions in negative existentials, shown in Figure 10, a two factor mixed ANOVA shows a significant main effect for group $(\mathrm{f}(2,29)=16.4$, $p<0.001)$, a significant main effect for sentence type $(\mathrm{f}(2.8,80)=7, p<0.001)$ and a borderline interaction $(f(5.5,80)=2.204, p=0.056)$. Post hoc Tamhane's T2 tests show that native controls and advanced L2ers do not differ from each other, while intermediates perform differently from both native controls $(p<0.005)$ and advanced L2ers $(p<0.01)$. According to one factor repeated measures ANOVAs, native controls and intermediate L2ers show no significant differences between the 4 types of ungrammatical affirmative existentials, while advanced L2ers reject ungrammatical proper names significantly more often than definite articles $(p<0.05)$.

Finally, we consider results from our control sentences, in order to establish that participants have no general problems with definite and indefinite subjects and that they do not adopt strategies such as accepting all indefinites and rejecting all definites in our task. Results are presented in Figure 11.

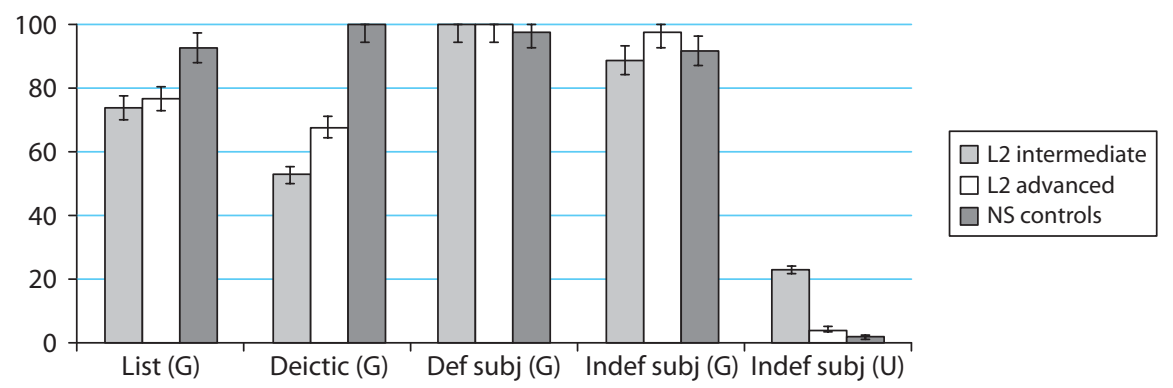

Figure 11. Control items: acceptance by Turkish-speaking L2ers (\%) 
Considering list and deictic contexts, as discussed above, in such cases, it is possible for a definite expression to co-occur with there. All subjects accept list readings as being natural. In other words, they are prepared to accept sentences involving there followed by a definite DP, which suggests that they are not simply following a strategy of rejecting all sentences involving definites, something which might otherwise account for their successful performance on the existentials. A two factor mixed ANOVA comparing list and deictic readings shows a significant effect for group $(\mathrm{f}(2,29)=6.7, p<0.005)$, no effect for sentence type $(\mathrm{f}(1,29)=1.6, p=0.223)$ and a borderline significant interaction $(\mathrm{f}(2,29)=3.3, p=0.053)$. Post hoc Tamhane's T2 tests show that native controls perform significantly better than both advanced $(p<0.05)$ and intermediate $(p<0.01)$ L2ers, while the two learner groups do not differ from each other. According to one factor repeated measures ANOVAs, for the native speakers and the advanced group there is no significant difference between acceptances of list and deictic readings; however, the intermediate subjects accept deictic readings less readily than list readings $(f(1,11)=5, p<0.05)$.

As for grammatical $(G)$ definite and indefinite subjects, performance was at or close to ceiling. The ungrammatical $(\mathrm{U})$ sentences involving subjects with indefinite articles were strongly rejected by the advanced group and the native speakers, and also rejected (to a slightly lesser extent) by the intermediate group. Results from these grammatical and ungrammatical sentence types suggest that the L2ers were not simply following a strategy of accepting all sentences involving indefinite subjects and rejecting all definites, which might otherwise account for their accuracy with existentials.

\subsection{Experiment 2: Russian-speaking L2ers}

\subsubsection{Subjects}

Subjects in the second experiment were adult Russian-speaking L2 learners of English, of intermediate $(n=10)$ and advanced $(n=15)$ proficiency, as determined by the same cloze test as was used for the Turkish speakers. The L2ers were tested in Montreal, Canada. Their average age of arrival in Canada was 29 (range 15-42 years) and their average age at the time of testing was 32 years and 10 months (range 19-42 years). Their knowledge of English was based on a combination of instruction in English as a foreign language in school and/or at university (starting from age of 12 years and 5 months, on average) and naturalistic exposure after arrival in Canada, for an average of 3 years 9 months (range 0-14;6 years). Because of the minor modifications to the task after it was taken by the Turkish speakers, a different control group of 17 native speakers of English was tested. 


\subsubsection{Results}

Once again, we start by presenting, in Figure 12, the overall results, collapsing articles and other determiners, and comparing grammatical (i.e. weak) cases with ungrammatical (i.e. strong), in both affirmative and negative existentials. A two factor mixed ANOVA shows a significant main effect for group $(\mathrm{f}(2,39)=6.1$, $p<0.005)$, a significant main effect for sentence type $(\mathrm{f}(2.4,93.8)=611.1, p<0$. $001)$ and a significant interaction $(f(4.8,93.8)=14.9, p<0.001)$, due to the fact that the advanced group accepts grammatical negative existentials less readily than grammatical positive existentials. Post hoc Scheffé tests show no significant differences between native controls and advanced L2ers, while the differences between controls and intermediate L2ers is significant $(p<0.01)$. According to paired ttests, participants show a significant difference in acceptance of grammatical and ungrammatical existentials, whether affirmative or negative $(p<0.001)$. Crucially, both the intermediate and advanced L2ers reject definite DPs in negative existentials.

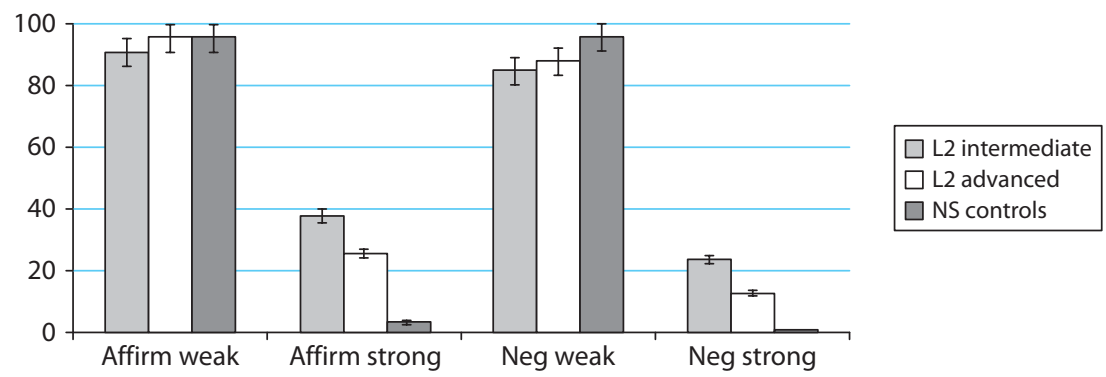

Figure 12. English existentials: acceptance by Russian-speaking L2ers (\%)

Results on the crucial ungrammatical sentences are shown in Figure 13 (affirmatives) and Figure 14 (negatives), divided into the same subtypes as before, namely definite articles, proper names, possessives and strong quantifiers. Once again, these are broken down in order to see whether there are greater problems with

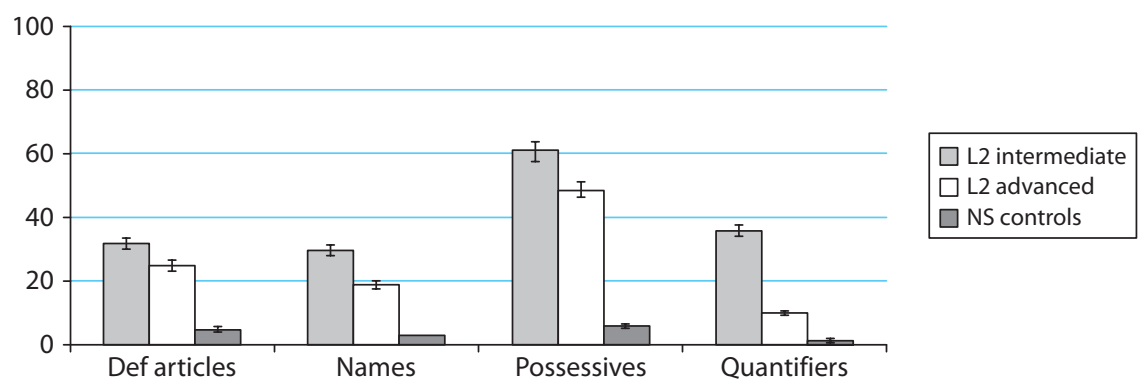

Figure 13. Ungrammatical affirmative existentials: acceptance by Russian-speaking L2ers (\%) 
articles (not found in the L1) than with other determiners. This turned out not to be the case.

As far as ungrammatical affirmatives are concerned, a two factor mixed ANOVA shows a significant main effect for group $(f(2,39)=14.8, p<0.0001)$, a significant main effect for sentence type $(\mathrm{f}(3,117)=13.5, p<0.0001)$ and a significant interaction $(f(6,117)=3.4, p<0.01)$, due to the L2ers' performance on the possessives (see below). Post hoc Tamhane's T2 tests reveal that native controls perform better than L2ers $(p<0.01)$, while the two L2 groups perform similarly, with no significant difference between them.

As can be seen in Figure 13, while the advanced L2 group appropriately rejects existentials with definite articles, proper names and quantifiers, they accept possessives almost $50 \%$ of the time. The intermediate learners are slightly more likely to accept the ungrammatical items in each subcondition, with possessives, again, being particularly problematic (61\%). According to one factor repeated measures ANOVAs, native controls show no significant differences between the 4 types of ungrammatical affirmative existentials, while advanced L2ers accept ungrammatical possessives significantly more often than the other types $(p<0.05)$; for the intermediate L2ers, the only significant difference is between ungrammatical possessives and proper names $(p<0.02)$.

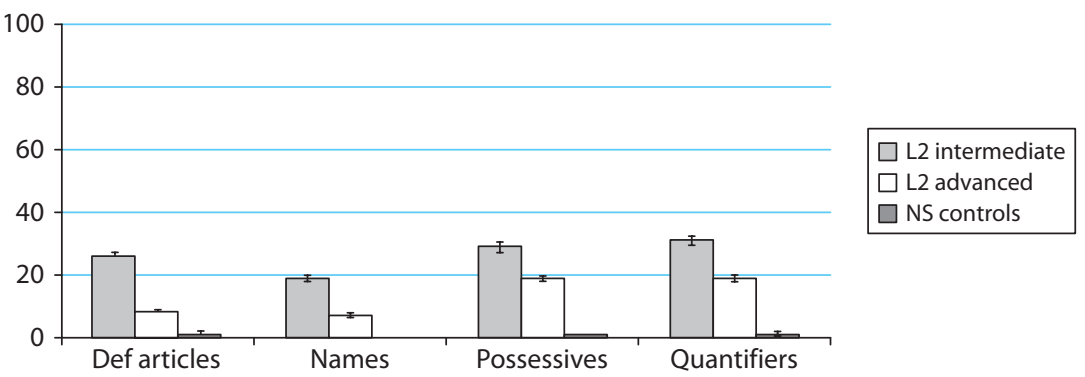

Figure 14. Ungrammatical negative existentials: acceptance by Russian-speaking L2ers (\%)

As for negative existentials (Figure 14), both L2 groups mostly reject all four subtypes. A two factor mixed ANOVA shows a significant main effect for group $(\mathrm{f}(2$, $39)=13.4, p<0.0001)$, no effect for sentence type $(\mathrm{f}(2.8,107.9)=1.9, p=0.1)$ and no interaction $(\mathrm{f}(5.5,107.9)=0.5, p=0.8)$. Post hoc Tamhane's T2 tests show that native controls perform better than L2ers $(p<0.02)$, while the two L2 groups do not differ from each other.

Comparing Figures 13 and 14, L2ers are better at rejecting possessive negative existentials, which are grammatical in the L1, than possessive affirmative existentials, which are ungrammatical $(p<0.01)$. There are no statistically significant 
differences in rejections of affirmative versus negative existentials across any of the other subtypes.

Finally, once again, we present the results from some of the other sentence types which were included in the task in order to control for the possibility that L2ers were using strategies such as accepting all indefinites and rejecting all definites. As Figure 15 shows, deictic and list readings were accepted by both learner groups; performance on grammatical definite and indefinite subjects was at or close to ceiling, and ungrammatical indefinite subjects were rejected.

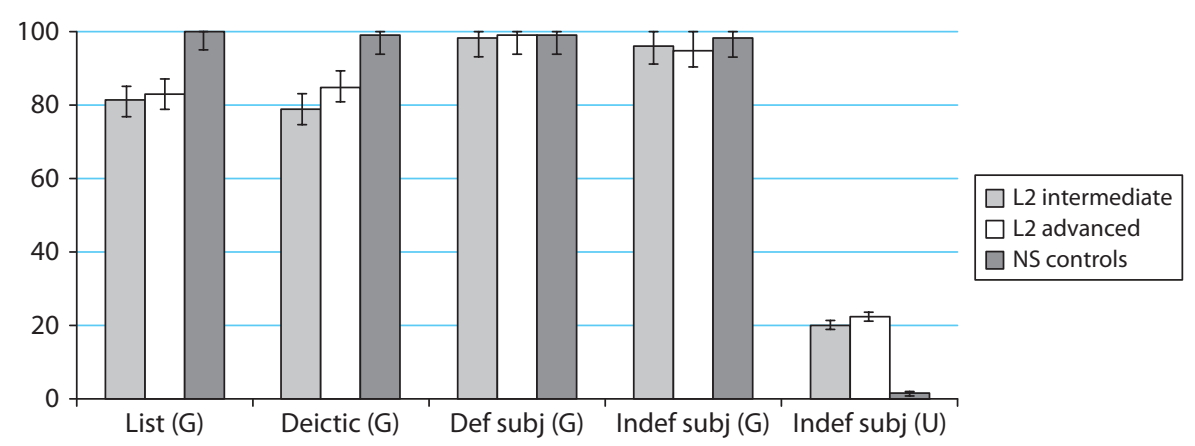

Figure 15. Control items: acceptance by Russian-speaking L2ers (\%)

A two factor mixed ANOVA comparing list and deictic readings shows a significant effect for group $(\mathrm{f}(2,39)=5.9, p<0.01)$, no effect for sentence type ( $\mathrm{f}(1$, $39)=0.03, p=0.873)$ and no interaction $(f(2,39)=0.1, p=0.91)$. Post hoc Scheffé tests show that native controls perform significantly better than both advanced $(p<0.05)$ and intermediate $(p<0.05)$ L2ers, while the two learner groups do not differ from each other $(p=0.9)$.

\subsection{Interim summary: L2 groups}

To summarize so far, we have found, for both L2 experiments, that advanced subjects differ very little from the native speaker controls. The intermediate level subjects also distinguish between existentials with strong and weak DPs, rejecting the former even when they are permitted in the L1, as is the case for negative existentials in both Turkish and Russian. All groups differ in their treatment of definite expressions in other contexts (list and deictic readings) compared to existentials, whether affirmative or negative.

There is, however, one noteworthy difference in performance across the two studies. As can be seen in Figure 13, the Russian-speakers, at both proficiency levels, accepted possessives (which are strong) at least $50 \%$ of the time in affirmative existentials, in contrast to the Turkish speakers (see Figure 9). It remains unclear 
why there are differences between the two L1 groups for the possessives, or why possessives (in contrast to other definite expressions) are accepted at all. ${ }^{17}$

So far, we have taken it for granted that the L1s differ from the L2 with respect to definite expressions in negative existentials. In the next section, we report on two experiments which specifically explore whether this is indeed the case, involving native speakers of Turkish judging a Turkish version of our test and native speakers of Russian judging a Russian version.

\subsection{Experiments 3 and 4}

\subsubsection{Subjects}

As described above, our task was translated into Turkish and Russian and was similar to the English version, except that there were fewer sentences in total. The Turkish task was administered in Turkey and was taken by 17 adult native speakers, while the Russian task was administered to 22 adult Russian native speakers in Russia and the Ukraine (the latter group having limited knowledge of Ukrainian).

\subsubsection{Results}

Figure 16 compares the overall performance of the Turkish and Russian speakers on affirmative and negative existential sentences involving weak and strong determiners. Crucially, the results confirm that these two languages differ from English in that negative existentials with strong determiners are deemed acceptable. A two factor mixed ANOVA shows a significant main effect for group $(\mathrm{f}(1,37)=5.3$, $p<0.05)$, a significant main effect for sentence type $(\mathrm{f}(3,37)=337.1, p<0.0001)$ and a significant interaction $(f(3,37)=337.1, p<0.005)$. The significant main effect for group and the interaction are due to the affirmative weak condition, which Russian speakers accept somewhat less readily than Turkish speakers; this is orthogonal to the issues that we are interested in. Importantly, according to paired t-tests, participants from both groups show a significant difference in acceptance of grammatical and ungrammatical affirmative existentials $(p<0.0001)$, and no difference between weak and strong negative existentials.

In Figure 17, we compare performance on affirmative existentials - broken down into 3 types of strong DP subjects (ungrammatical in both languages) with performance on equivalent sentence types in negative existentials (grammatical in both languages). A two factor mixed ANOVA shows no main effect for group $(f(1,37)=2.2, p=0.143)$, a significant main effect for sentence type $(\mathrm{f}(3.3,121.1)=366.9, p<0.001)$ and a significant interaction $(\mathrm{f}(3.3,121.1)=3.5$, $p<0.05)$. According to paired t-tests, there is a significant difference between acceptance of the affirmative versus the negative versions of the existentials for each of the subtypes $(p<0.001)$. This is true of both language groups, as confirmed by 


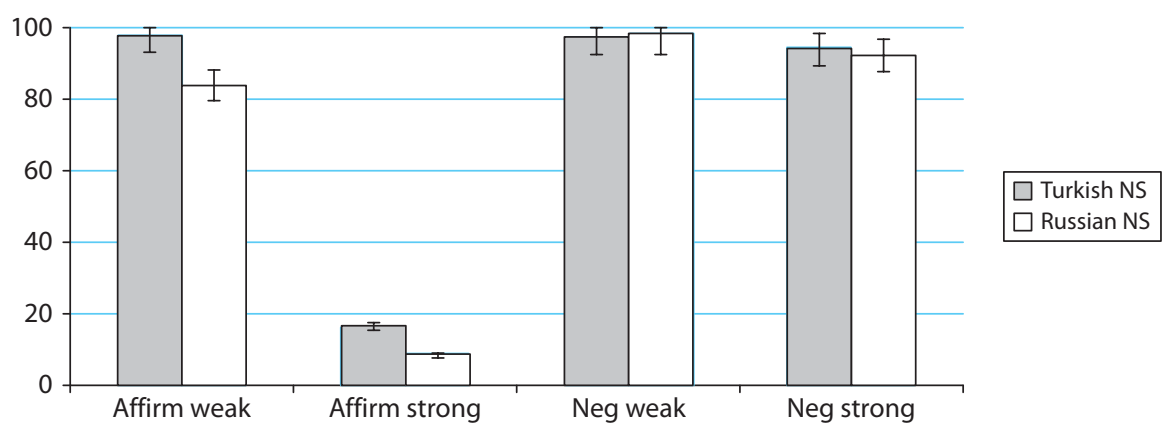

Figure 16. Turkish and Russian existentials: acceptance by native speakers (\%)

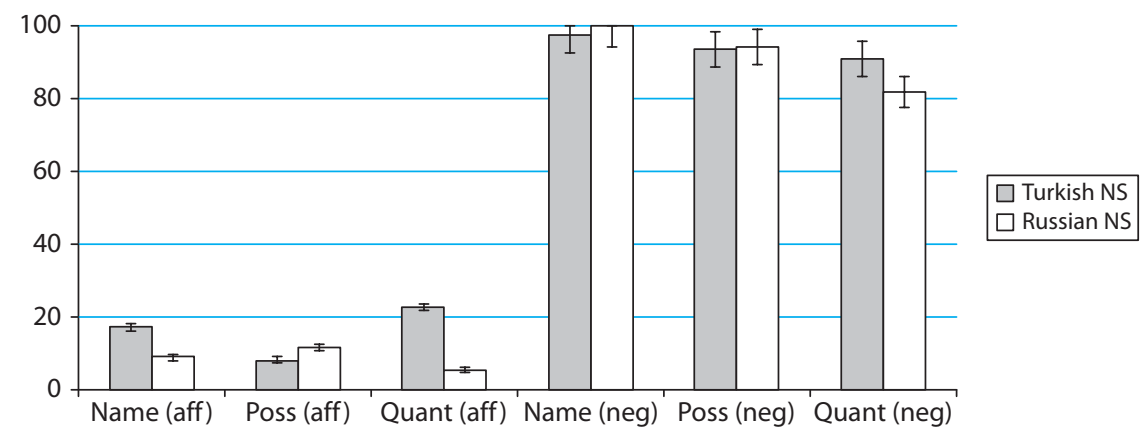

Figure 17. Strong affirmative and negative existentials in Turkish and Russian: acceptance by native speakers (\%)

one factor repeated measures ANOVAs (Turkish speakers: $f(2.6,41.9)=123.3$, $p<0.001$; Russian speakers: $\mathrm{f}(2.5,52.6)=277.2, p<0.001)$. The significant interaction effect is due to a minor difference between the two groups: Russian speakers accept strong quantifiers in negative existentials somewhat less readily than proper names $(p<0.05)$, while Turkish speakers observe no such difference.

\subsection{Comparison}

We end with a comparison of the results from all the experiments discussed here, focusing on the performance of native speakers and advanced L2ers on the main sentence types that we are interested in. As shown in Figure 18, the two L2 groups (judging English), the native speakers of English (judging English), the native speakers of Turkish (judging Turkish) and the native speakers of Russian (judging Russian) all perform very similarly on three of the four sentence types under consideration. In particular, affirmative and negative existentials with weak determiners are consistently accepted, while affirmative existentials with strong determiners are rejected. Where the groups differ is in the case of negative existentials with 


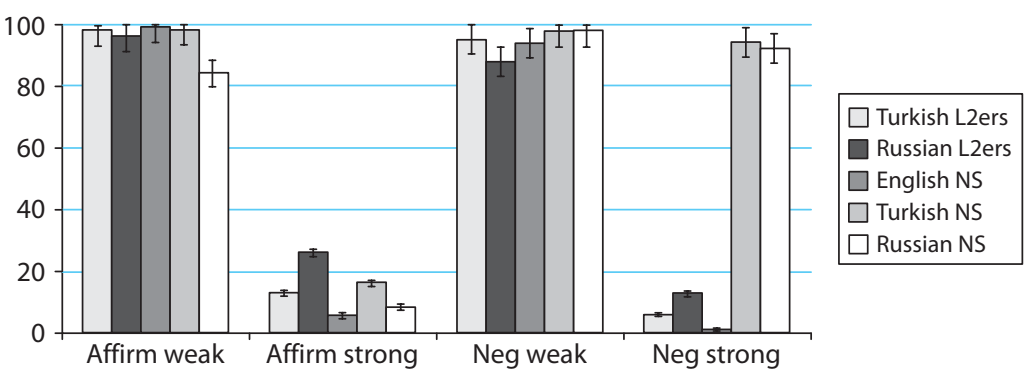

Figure 18. English, Turkish and Russian existentials compared (\%)

strong determiners: the L2ers pattern like native speakers of English in rejecting these sentences in their L2, in contrast to native speakers of Turkish and Russian who overwhelmingly accept them in their L1. A two factor mixed ANOVA shows a significant main effect for group $(\mathrm{f}(4,76)=26.9, p<0.0001)$, a significant main effect for sentence type $(\mathrm{f}(3,76)=942.2, p<0.0001)$ and a significant interaction $(f(12,76)=85.5, p<0.0001)$. Post hoc tests show no significant difference between native English speakers and advanced L2ers, while the difference between each of the latter three groups and native speakers of Russian and Turkish (judging their L1s) is significant $(p<0.05)$. Participants show no significant difference in acceptance of affirmative and negative existentials with weak determiners. However, there was a significant difference in acceptance of affirmative and negative existentials with strong determiners $(p<0.0001)$; the significant interaction is due to a difference in the performance of native speakers of Russian and Turkish (judging their L1s) and the other three groups of participants on negative existentials with strong determiners.

\section{Discussion}

To summarize the results so far, we have found that L2ers of intermediate and advanced levels of proficiency whose L1s are Turkish and Russian differentiate between grammatical and ungrammatical cases of there-insertion. They reject definite/strong DPs in affirmative as well as negative existentials, with the advanced L2ers, almost without exception, showing no significant differences from the native speaker controls. Furthermore, performance on sentences which are not existential (list, deictic and other grammatical and ungrammatical items) suggests that accuracy on the DE does not reflect a general bias towards accepting all indefinites and rejecting all definites. Results from Turkish and Russian speakers taking the task in Turkish and Russian respectively show that it is indeed the case that the DE in these languages works differently from English as far as negative existentials are 
concerned, indicating that successful performance by the L2ers cannot be attributed to L1 transfer, since participants rejected strong negative existentials in the L2.

Some other possible explanations for the L2ers' success can also be eliminated on the basis of our results. For example, it has been suggested to us that properties of English there-insertion are instructed, with L2ers being taught that there is a ... is grammatical and there is the ... ungrammatical (Boping Yuan, personal communication). However, in list and deictic contexts, our subjects accepted grammatical cases of there is the ..., suggesting that they had no general prohibition against definites with there. Furthermore, it is unlikely that instruction distinguishes between weak and strong determiners in general and yet our subjects had no problem making this distinction. A related suggestion (Robert Bley-Vroman, personal communication) is that L2ers are sensitive to the fact that existential expressions like there is $a \ldots .$. are quite frequent in the input, in contrast to expressions like there is the..., so that they may assume on grounds of frequency that only the former are permitted; alternatively, they may treat there is a ... as an unanalyzed chunk on the basis of its frequency (Trenkic, 2007). Against these proposals is the fact that our L2 groups had no difficulty in accepting there is the... when it was appropriate (i.e. in list and deictic contexts). Furthermore, it seems unlikely that a frequency or chunk based explanation can extend to other weak and strong determiners, which are in general much less frequent in the input than articles but which were treated appropriately.

It seems, then, that L2ers are successful in acquiring how the DE plays out in the L2, regardless of how it works in the L1, and that they do not achieve this on the basis of instruction or input frequency. Rather, given the ease with which L2 $\mathrm{DE}$ effects are acquired, the results suggest that some universal principle(s) may be at work. Indeed, the fact that there are cross-linguistic differences, at least with respect to negative existentials, implicates some kind of formal parametric difference between languages. What is not yet clear is what that difference is or what property of the English input signals to Turkish and Russian speakers that negative existentials work differently in the L1 and the L2.

To examine this question, we turn now to a discussion of the pragmatic, semantic and syntactic properties of the construction, with an emphasis on crosslinguistic differences in how these play out and the possible role that these differences might play in providing 'triggering' data to allow an L2 learner to arrive at the appropriate representation.

We have already touched on some of the pragmatic accounts of the DE. While these vary in detail, they share the assumption that absence of presupposition is crucially implicated; only DPs which do not presuppose the existence of their referents are natural in existentials. In other words, the subject must be novel, hearernew, non-anaphoric or in focus (e.g. Abbott, 1993; Rando \& Napoli, 1978; Ward \& 
Birner, 1995; see McNally, in press, for an overview). Indeed, on many of these accounts, a pragmatic explanation of the restriction is considered not just necessary but also sufficient. Nevertheless, absence of presupposition cannot in fact be the only determinant of the restriction. Such a proposal appears to work for languages like English; however, in languages like Turkish and Russian, the presupposition requirement does not hold for subjects of negative existentials, where definite expressions are permitted, suggesting that a different account is necessary.

Another kind of explanation, starting with Milsark (1977), is semantically based. Certain semantic properties are consistently associated with existential sentences across languages. The most important one is the definiteness restriction on the pivot DP which specifies the individual whose existence is under discussion (e.g. a customer in There is still a customer in the store). A second property is a restriction on the coda (e.g. in the store). The coda must be a stage-level predicate describing an accidental property; it cannot be an individual-level predicate describing a permanent or essential property (e.g. ${ }^{\star}$ There is a customer aggressive). Discussion within semantic accounts has centred on the semantic status of these elements, especially on which of them serves as the main predicate (e.g. Barwise \& Cooper, 1981; Keenan, 1987). Another question is whether or not the pivot should be associated with quantificational force (Barwise \& Cooper, 1981; Keenan, 1987; McNally, 1998; Milsark, 1977). There are counterarguments to each of the analyses proposed so far (see, for example, McNally, in press; Zucchi, 1995, for overviews). As is the case for pragmatic accounts, semantic explanations appear to break down in the face of the cross-linguistic variation shown by negative existentials.

While some researchers have offered purely syntactic accounts of the DE (notably, Safir, 1989), there has been a tendency in recent years for syntactic accounts to be rejected. However, it is our contention that the cross-linguistic differences that we have observed can best be accounted for syntactically (probably together with pragmatic and/or semantic explanations, since we concur with McNally (in press) that there is no reason to assume that only one kind of explanation underlies the phenomenon). Here, we sketch an analysis which draws on the by now generally accepted view that there are multiple structural positions for categories such as subjects, verbs, indefinites, and negatives.

For the purposes of this account, we assume that there is a tight connection between syntactic structure and semantic interpretation. Following Diesing (1992), we assume that for a DP to be interpreted as an indefinite, it must be structurally within the domain over which 'existential closure' applies. Conversely, a DP that is interpreted as definite must be outside the domain of existential closure. Certain syntactic operations are available that alter the relative positions of the sentential elements between their pronounced and interpreted positions (e.g. Quantifier Raising and reconstruction). 
The existence of the DE in English can be taken to indicate that subject DPs in existential constructions cannot reach an interpretation position outside the domain of existential closure, and thus only DPs allowed within the domain of existential closure are allowed in existential constructions. The availability of definite subject DPs in Turkish and Russian negative existential constructions indicates that in negative sentences - but not affirmative ones - the subject can escape the domain of existential closure prior to interpretation.

There are two logical possibilities to account for the asymmetry between affirmative and negative sentences in Turkish and Russian: either (i) subjects have a wider range of movement options in negative sentences, or (ii) the domain of existential closure is smaller in negative sentences. However, it is unclear what would motivate additional movement of subjects in negative sentences, and there are no obvious parallels to draw with other known phenomena involving subject raising. Accordingly, we pursue the second view here.

Existential closure applies at the VP level, but it also applies in the immediate scope of negation (Heim, 1982). Larson (1985) uses this to explain why an indefinite like a book cannot take scope over need in John doesn't need a (particular) book, while it can in John needs a (particular) book. In English, where negation is outside the VP, the consequences of existential closure in the immediate scope of negation are minimal; by the time existential closure would have been triggered by negation, it will have already been triggered at the VP. However, if negation were lower than VP, then, existential closure would occur sooner in negative sentences than in affirmative sentences.

For Turkish, Kelepir (2001) argues that yok ('not exist') is not a verb, but rather a participle; as such, it is expected to remain low in the structure. If this is correct, we have all of the ingredients necessary to explain the asymmetry, at least in Turkish: in negative existential constructions, the morpheme carrying the negative interpretation remains within the VP triggering existential closure earlier than it would be triggered in an affirmative sentence.

As previously mentioned, the parametric variation in the behaviour of the $\mathrm{DE}$ appears to present a kind of 'subset problem', insofar as direct evidence of the unacceptability of definites in English negative existentials cannot be derived from the L2 input. However, we have seen that L2ers succeed in acquiring the English prohibition on definites in such cases, even where the L1 allows it. There must, therefore, be some trigger in the L2 input, allowing this difference between the L1 and the $\mathrm{L} 2$ to be acquired.

On the account just given, the difference between languages in which definites are allowed in negative existential constructions lies not in the properties of the existential constructions themselves, but rather in the structural position of negation. In this connection, it is of interest to note that one aspect of both Turkish and 
Russian that differentiates them from English is the existence of a special morphological form to express 'not exist' (net in Russian, yok in Turkish). One possibility is that the presence or absence of this form can serve as a trigger for acquisition. That is, the fact that negative existential constructions in English are formed with the regular form of sentential negation (be not) and not with a special suppletive form, leads L2ers to interpret negation above the VP in such constructions in the L2. While it is unlikely to be an absolute universal that any language having a suppletive form of 'not exist' should allow definite DPs in negative existentials, the existence of this form in a language can be seen to serve as an important cue for putting negation in a lower structural position. Correspondingly, the absence of such a form in the L2 motivates the placement of negation higher in the structure. Once that knowledge is acquired, the unacceptability of definite DPs in negative existential constructions follows from universal, general principles that govern the distribution of definite and indefinite DPs.

In conclusion, our results suggest that L2ers do not suffer from any kind of deficit relating to realization of definiteness in existential constructions. On the contrary, L2ers are very sensitive to subtle restrictions on definiteness in the L2, even when the L1 and the L2 differ in significant respects. This is so even though, as mentioned in the introduction, L2ers are frequently reported to have considerable problems in the production of articles, including L2ers who observe the DE (White, 2003). This contrast in success on interpretation versus production suggests that a prosodic explanation, an explanation which is independent of the issue of definiteness, may provide the most appropriate account of production difficulties (Goad \& White, 2009). Indeed, our findings suggest that researchers should be wary of taking problems with surface morphology (such as the commonly reported omission or misuse of articles) as indicative of deeper problems with underlying representations.

\section{Acknowledgments}

We are grateful for funding from the Social Sciences and Humanities Research Council of Canada and the Fonds québécois de la recherche sur la societé et la culture. Thanks to Will Dalton, Larissa Nossalik and Müberra Özçelik for their assistance with various aspects of this research, and to the anonymous reviewers for their helpful comments and suggestions. 


\section{Notes}

1. Following Rando and Napoli (1978), it has been the practice in the literature to refer to such cases as list readings, a practice we also adopt. However, not all researchers agree that cases like (3b) really constitute lists, especially in single item cases; see, for example, Abbott (1993).

2. Another kind of exception involves cases which are definite in form but indefinite in meaning, as in (i). We do not investigate such cases.

(i) There was the most amazing animal at the zoo.

3. The Turkish indefinite bir is not identical in distribution to English $a$, and it can be omitted. Bare nouns in Turkish can be interpreted as indefinite or definite, depending on a number of factors, including word order and case-marking. Bare nouns typically receive an indefinite interpretation in object position and are potentially ambiguous elsewhere (Kornfilt, 1997; Lyons, 1999). (See also footnote 5.)

4. (6b) can be rendered grammatical by means of focus, as discussed below.

5. A bare noun such as adam 'man' in an affirmative existential like (i) must be interpreted as indefinite, whereas in a negative existential like (ii) it is ambiguous between an indefinite and a definite interpretation.

(i) Adam var (man exist; 'there is a man')

(ii) Adam yok (man not.exist; 'there isn't a/the man').

6. In particular, this is the situation in the non-present tenses. In the present tense, the affirmative predicate est' signals existentiality, while the null copula is normally indicative of locativity. According to our analysis, the present tense negative predicate net also signals existentiality.

7. Where the genitive of negation is optional, its presence is normally correlated with an indefinite or non-specific interpretation.

8. To allow for pairs contrasting existentials and true locatives, the examples in (10) and (11) involve non-present tenses (see footnote 6). In the future and in the past, non-existence is expressed with the usual negative particle ne and the verb $b e$; most scholars agree that in the nonpresent tenses, for a negative existential interpretation to be possible, subjects must be marked with genitive and be must be 'impersonal' (exhibiting non-agreement with the subject) (e.g. Babby, 1980, amongst many others). As for the affirmative form of non-present tense existentials, existence is expressed with inflected be which agrees with its nominative subject. As a result, it can be hard to distinguish between locative interpretations and actual existentials, which is why word order has often been taken to be criterial in such cases (e.g. Babby, 1980).

9. However, Drury et al's native speaker control group also showed N400 effects, typically associated with lexico-semantic effects, which were not found in any of the L2 groups.

10. Aspects of this work are reported in White, Belikova, Hagstrom, Kupisch and Özçelik (2009) (for the Turkish-speaking L2ers), Belikova, Hagstrom, Kupisch, Özçelik and White (2010) (for the Russian-speaking L2ers), and White, Belikova, Hagstrom, Kupisch and Özçelik (in press) (for the native speakers of Turkish and Russian). 
11. We also included sentences which involved ungrammatical indefinite objects, to increase the number of ungrammatical indefinites in the task. However, our results only address sentences involving subjects, so these are not considered here.

12. The translations were not necessarily literal, as some of our contexts and/or test items did not work identically in all 3 languages, for cultural or pragmatic reasons. Therefore, some changes were introduced to make the items felicitous/appropriate to each language. Compare, for example, the minor differences between Figures 4, 6 and 7.

13. In addition to strong quantifiers, as shown in (20b) and (21b), and proper names (Figures. 6 and 7), possessive determiners were also tested in this category.

14. In some cases, there are minor discrepancies between the statistical analyses reported here and those in our earlier papers. This is, in part, because, in the present paper, we use degrees of freedom that reflect corrected values (necessary when Mauchly's test of sphericity indicates the violation of the assumption of sphericity). The effect of correcting degrees of freedom is a change in the significance of the value of $\mathrm{F}$.

15. This was a multiple-choice test, involving a passage with 30 blank words; for each blank there were 4 answers provided, only one of which was appropriate. The test was prepared and validated by the Department of Psychology, University of Ottawa, and previously available from their website.

16. Error bars in all figures are set at $5 \%$.

17. One possible explanation is that possession in English can in fact be signified by means of weak DPs, such as a book of mine. Indeed, possessives in some languages can alternate between strong and weak readings under certain conditions, as is the case for Turkish. However, as it was the Russian speakers who had the greatest difficulty with possessives, it is not clear that such an explanation is appropriate for them.

\section{References}

Abbott, B. (1993). A pragmatic account of the definiteness effect in existential sentences. Journal of Pragmatics, 19, 39-55.

Babby, L.H. (1980). Existential Sentences and Negation in Russian. Ann Arbor, Michigan: Karoma Publishers.

Barwise, J., \& Cooper, R. (1981). Generalized quantifiers and natural language. Linguistics and Philosophy, 4, 159-220.

Beaver, D., Francz, I., \& Levinson, D. (2005). Bad subject: (Non-)canonicality and NP distribution in existentials. In E. Georgala, \& J. Howell (Eds.), Proceedings of SALT XV (pp. 19-43). Ithaca, NY: CLC Publications.

Belikova, A., Hagstrom, P., Kupisch, T., Özçelik, Ö., \& White, L. (2010). Definiteness in positive and negative existentials in the L2 English of Russian speakers. In J. Costa, A. Castro, M. Lobo, \& F. Pratas (Eds.), Proceedings of GALA 2009 (pp.28-38). Cambridge, UK: Cambridge Scholars Publishing.

Borschev, V., \& Partee, B.H. (1998). Formal and lexical semantics and the genitive in negated existential sentences in Russian. In Ž. Bošković, S. Franks, \& W. Snyder (Eds.), Formal 
Approaches to Slavic Linguistics 6: The Connecticut Meeting 1997 (pp.75-96). Ann Arbor: Michigan Slavic Publications.

Diesing, M. (1992). Indefinites. Cambridge, MA: M.I.T. Press.

Drury, J., White, E., White, L., \& Steinhauer, K. (2009). Brain potentials and the processing of (in)definiteness in late learners of English. Poster presented at the Cognitive Neuroscience Society, San Francisco, March 2009.

Enç, M. (1991). The semantics of specificity. Linguistic Inquiry, 22, 1-25.

Freeze, R. (1992). Existentials and other locatives. Language, 68, 553-595.

Garcia-Mayo, M., \& Hawkins, R. (Eds). (2009). Second language acquisition of articles: Empirical findings and theoretical implications. Amsterdam: John Benjamins.

Goad, H., \& White, L. (2009). Prosodic transfer and determiners in Turkish-English interlanguage. In N. Snape, Y.k. I. Leung, \& M. Sharwood Smith (Eds.), Representational deficits in L2 acquisition (pp. 1-26). Amsterdam: John Benjamins.

Heim, I. (1982). The semantics of definite and indefinite noun phrases. Unpublished doctoral dissertation, University of Massachusetts, Amherst.

Huebner, T. (1985). System and variability in interlanguage syntax. Language Learning, 35, 141-163.

Ionin, T., Ko, H., \& Wexler, K. (2004). Article semantics in L2 acquisition: The role of specificity. Language Acquisition, 12, 3-69.

Jung, H. (2011). The syntax of the be-possessive: Parametric variation and surface diversities. Amsterdam: John Benjamins.

Keenan, E. (1987). A semantic definition of 'indefinite NP'. In E.J. Reuland, \& A.G.B. ter Meulen (Eds.), The representation of (in)definiteness (pp.43-70), Cambridge, MA: MIT Press.

Kelepir, M. (2001). Topics in Turkish syntax: Clausal structure and scope. Unpublished doctoral dissertation, Massachusetts Institute of Technology.

King, E., Steinhauer, K., \& White, L. (2006). The definiteness effect in L2 acquisition: What can event-related brain potentials tell us? Paper presented at Generative Approaches to Second Language Acquisition 8, Banff, April 2006.

Kondrashova, N. (1996). The syntax of existential quantification. Unpublished doctoral dissertation, University of Wisconsin, Madison.

Kornfilt, J. (1997). Turkish. London: Routledge.

Lardiere, D. (2004). Knowledge of definiteness despite variable article omission in second language acquisition. In A. Brugos, L. Micciulla, \& C.E. Smith (Eds.), Proceedings of the 28th Annual Boston University Conference on Language Development (pp.328-339). Somerville, MA: Cascadilla Press.

Larson, R. (1985). On the syntax of disjunction scope. Natural Language and Linguistic Theory, $3,317-264$.

Leonetti, M. (2008). Definiteness effects and the role of the coda in existential constructions. In A. Klinge, \& H. Hoeg-Muller (Eds.), Essays on nominal determination: From morphology to discourse management (pp.131-162). Amsterdam: Benjamins.

Lumsden, M. (1988). Existential sentences: Their structure and meaning. Croom Helm, London. Lyons, C. (1999). Definiteness. Cambridge: Cambridge University Press.

McNally, L. (1998). Existential sentences without existential quantification. Linguistics and Philosophy, 21, 353-392.

McNally, L. In press. Existential sentences. In C. Maienborn, K. von Heusinger, \& P. Portner (Eds.), Semantics: An international handbook of natural language meaning, Vol. II. Berlin: Walter de Gruyter Press. 
Milsark, G.L. (1977). Toward an explanation of certain peculiarities of the existential construction in English. Linguistic Analysis, 3, 1-29.

Özçelik, Ö., \& Nagai, M. (2011). Multiple subject positions: A case of perfect match between syntax and prosody. In M. Byram, \& B. Tomaszewicz (Eds.), Proceedings of the 28th West Coast Conference for Formal Linguistics (WCCFL 28) (pp.303-312). Somerville, MA: Cascadilla Press.

Padučeva, E. (2000). Definiteness effect: The case of Russian. In K. von Heusinger (Ed.), Reference and anaphoric relations (pp. 133-146). Dordrecht: Kluwer.

Partee, B.H., \& Borschev, V. (2002). Genitive of negation and scope of negation in Russian existential sentences. In J. Toman (Ed.), Formal Approaches to Slavic Linguistics: The Ann Arbor Meeting 2001 (FASL 10) (pp. 181-200). Ann Arbor: Michigan Slavic Publications.

Partee, B.H., \& Borschev, V. (2007). Existential sentences, BE, and the genitive of negation in Russian. In I. Comorovski, \& K. von Heusinger (Eds.), Existence: Semantics and Syntax (pp. 147-190). Dordrecht: Springer.

Rando, E., \& Napoli, D.J. (1978). Definites in there-sentences. Language, 54, 300-313.

Robertson, D. (2000). Variability in the use of the English article system by Chinese learners of English. Second Language Research, 16, 135-172.

Safir, K. (1987). What explains the definiteness effect? In E. Reuland, \& A. ter Meulen (Eds.), The representation of (in)definiteness (pp.71-97). Cambridge, MA: M.I.T. Press.

Thomas, M. (1989). The acquisition of English articles by first- and second-language learners. Applied Psycholinguistics, 10, 335-355.

Trenkic, D. (2007). Variability in L2 article production: Beyond the representational deficit vs. processing constraints debate. Second Language Research, 23, 289-327.

Tsimpli, I-M., \& Mastropavlou, M. (2007). Feature interpretability in L2 acquisition and SLI: Greek clitics and determiners. In J. Liceras, H. Zobl, \& H. Goodluck (Eds.), The role of formal features in second language acquisition (pp. 142-183). Mahwah, NJ: Lawrence Erlbaum.

Ward, G., \& Birner, B. (1995). Definiteness and the English existential. Language, 71, 722-742.

White, L. (2003). Fossilization in steady state L2 grammars: Persistent problems with inflectional morphology. Bilingualism: Language and Cognition, 6, 129-141.

White, L. (2008a). Some puzzling features of L2 features. In J. Liceras, H. Zobl, \& H. Goodluck (Eds.), The role of features in second language acquisition (pp.301-326). Lawrence Erlbaum.

White, L. (2008b). Definiteness effects in the L2 English of Mandarin and Turkish speakers. In H. Chan, H. Jacob, \& E. Kapia (Eds.), Proceedings of the 32nd Annual Boston University Conference on Language Development (pp. 550-561). Somerville, MA: Cascadilla Press.

White, L., Belikova, A., Hagstrom, P., Kupisch, T., \& Özçelik, Ö. (2009). Restrictions on definiteness in L2 English. In J. Chandlee, M. Franchini, S. Lord \& G.M. Rheiner (Eds.), Proceedings of the 33rd Annual Boston University Conference on Language Development (pp.622-633). Somerville, MA: Cascadilla Press.

White, L., Belikova, A., Hagstrom, P., Kupisch, T., \& Özçelik, Ö. (In press). There aren’t many difficulties with definiteness: Negative existentials in the L2 English of Turkish and Russian speakers. Proceedings of GALANA 4. Somerville, MA: Cascadilla Proceedings Project.

Zucchi, A. (1995). The ingredients of definiteness and the definiteness effects. Natural Language Semantics, 3, 33-78. 


\author{
Authors' addresses \\ Lydia White \\ Dept of Linguistics \\ McGill University \\ 1085 Dr. Penfield Avenue \\ Montreal, QC H3A 1A7 \\ Canada \\ Tel: 5143984143 \\ lydia.white@mcgill.ca \\ Alyona Belikova \\ Dept of Linguistics \\ McGill University \\ 1085 Dr. Penfield Avenue \\ Montreal, QC H3A 1A7 \\ Canada \\ alyona.belikova@mail.mcgill.ca \\ Paul Hagstrom \\ CAS Linguistics Program \\ Dept of Romance Studies \\ Boston University \\ 621 Commonwealth Ave. \\ Boston, MA 02215 \\ hagstrom@bu.edu
}

Tanja Kupisch

Universität Hamburg

Institut für Romanistik

Von-Melle-Park 6

D-20149 Hamburg

tanja.kupisch@uni-hamburg.de

Öner Özçelik

Dept of Linguistics

McGill University

1085 Dr. Penfield Avenue

Montreal, QC H3A 1A7

Canada

oner.ozcelik@mail.mcgill.ca 